\title{
ТРАНСФОРМАЦИЯ ФИНАНСОВО-ПРАВОВЫХ ОТНОШЕНИЙ В УСЛОВИЯХ ЦИФРОВОЙ ЭКОНОМИКИ
}

В статье рассматриваются вопросы правового сопровождения активных процессов цифровизации, в том числе в сфере экономики. Государственная политика на активную цифровизацию экономических отношений нашла выражение в национальной программе «Цифровая экономика Российской Федерации», включающей в себя шесть федеральных проектов: «Нормативное регулирование цифровой среды», «Информационная инфраструктура», «Кадры для цифровой экономики», «Информационная безопасность», «Цифровые технологии» и «Цифровое государственное управление». Положения данной национальной программы стали предметом исследования в статье. Сегодняшний этап развития отличается процессами технологизации, цифровизации общественных отношений. Возникновение новых явлений цифровой экономики: большие данные, машиначитаемое право, нейротехнологии и искусственный интеллект; системы распределенного реестра (блокчейн); квантовые технологии; новые производственные технологии; промышленный интернет; компоненты робототехники и сенсорика; технологии беспроводной связи); технологии виртуальной и дополненной реальностей, LegalTech, FinTech требуют новых подходов к универсальному регулятору - праву.
Инновации в финансовой и банковской сферах, развивающиеся вне правового регулирования, сопровождаются серьезными рисками в экономической сфере. В прошлом году общественное движение «Криптоволя» выпустила Криптоманифест, где выдвигается требование к государству легализовать криптовалюту и не препятствовать ее обращению. К сожалению, сегодняшний оборот цифровых финансовых активов практически не подчиняется законам, обещанный к принятию в декабре закон о криптовалютах пока «благополучно» отклонен. Российская Федерация и другие страны пока не торопятся опосредовать законом новые общественные отношения, но следует отметить определённую активность отечественного законодателя за последние несколько лет, результатом которой стало принятие ряда важных нормативных положений по цифровым правам. Авторы статьи уделили внимание проблемам придания правового статуса таких цифровых финансовых активов, как: блокчейн, биткоин, криптовалюта.

Ключевые слова: право, закон, экономика, цифровая экономика, информационные технологии, финансовое право, финансовые инструменты, валюта, криптовалюта, биткоин, блокчейн.

\section{Smirnov, L. Botasheva, A. Leonov}

\section{TRANSFORMATION OF FINANCIAL AND LEGAL RELATIONS IN THE CONDITIONS OF DIGITAL ECONOMY}

The article deals with the issues of legal support of active digitalization processes, including the economic sphere. The state policy on active digitalization of economic relations found expression in the national program "Digital Economy of the Russian Federation", which includes six federal projects: "Law regulation of digital environment", "Information infrastructure", "Personnel for the digital economy", "Information security", "Digital Technologies" and "Digital Public Administration". The provisions of this national program were the subject of research in the article. The current stage of development is characterized by processes of technologization and digitalization of social relations. The emergence of new phenomena of digital economy: big data, machine law, neurotechnology and artificial intelligence; distributed registry systems (blockchain); quantum technologies; new production technologies; industrial internet; components of robotics and sensorics; wireless technology); technologies of virtual and augmented reality, LegalTech, FinTech require new approaches to the universal regulator - the law. Innovations in the financial and banking sectors, developing outside the legal regulation, are accompanied by serious risks in the economic sphere. Last year the public movement "Cryptovolya" released Cryptomanifest, where a requirement is claimed for the state to legalize cryptocurrency and not to hinder its circulation. Unfortunately, today's turnover of digital financial assets is almost not subject to the laws, the law on cryptocurrency promised for adoption in December has been "safely" rejected. The Russian Federation and other countries are still not in a hurry to mediate new social relations by law, but it should be noted that a certain activity of the domestic legislator over the past few years has resulted in the adoption of a number of important digital rights regulations. The authors of the article paid attention to the problems of giving legal status to such digitalization tools as: blockchain, bitcoin, cryptocurrency.

Key words: law, law, economics, digital economy, information technologies, financial law, financial instruments, currency, cryptocurrency, Bitcoin, blockchain 
Вновь принятая и обновленная стратегия развития информационного общества на 2017-2030 годы расширяет сферы применения информационных и коммуникационных технологий, направленных на развитие информационного общества и формирование национальной цифровой экономики. Построение цифровой экономики является глобальной задачей тысячелетия. Одним из главных элементов во всей системе будущей цифровой экономики, безусловно, являются законы. Актуальность правового регулирования внедрения и практического применения современных финансовых технологий вызвана новыми индикаторами развития современной экономики. Значимость создания нормативно-правовых инициатив по интеграции в российский рынок перспективных финансовых технологий определяется действующей экономической политикой.

Следует согласиться с мнением, выраженным в Концепции повышения эффективности права разработанной командой Симплоера и рабочей группой юристов о том, что по мере развития технологий изменятся не только законодательство но и сама модель взаимодействия государства и бизнеса. Существенная часть норм может быть алгоритмизирована, а регулирование стать машиночитаемым [11].

Разработка федеральных законов, сочетающихся с формированием подзаконных нормативных актов, содержащих механизмы практической реализации институтов цифровой экономики с тем, чтобы после принятия без промедлений заработала вся административно-правовая цепочка по правоприменению, является первоочередной задачей формирования цифровой экономики. Определяя роль права в вопросах глобальной цифровизации, представитель молодого поколения юристов Антон Вашкевич, смело отмечает, что право давно уже должно стать как электричество - незаменимым и незаметным [1] Актуальной публичной задачей является обеспечение прав человека, снятие ключевых правовых ограничений и создание качественного правового инструментария цифровой экономики.

Мировыми лидерами в цифровой экономике являются такие страны, как: США, Южная Корея Великобритания, Швеция, Финляндия, Япония, Китай, Германия, Франция, Испания и Индия, которые в свою очередь имеют большой опыт правового регулирования национальной цифровой экономики [2, с. 103-104].

В Российской Федерации цифрровая экономика находится в стадии своего становления и весьма динамического развития, получившая некое правовое оформление и государственную поддержку с момента принятия Распоряжения Правительства РФ от 28.07.2017 №1632-р «Об утверждении программы «Цифровая экономика Российской Федерации", которая направлена на реализацию государственной политики по созданию необходимых условий для развития цифровой экономики России [7].

Активное применение информационных технологий, в том числе в качестве финансовых ин- струментов является одной из наиболее самых обсуждаемых тем в последнее время. Проблемы построения цифровой экономики находится в фокусе внимания публичной власти. Блокчейн, биткоин, криптовалюта стали предметом рассмотрения на государственном уровне. Наблюдается активная блокчейнизация сектора экономики требующая адекватного правового регулирования, способного обеспечить права и законные интересы участников технологического процесса.

Цифровая экономика является новым объектом правового регулирования, вызванного глобализацией и повсеместным введением цифровых технологий, в связи с этим исследования в данной области единичны. Представителями юридической науки уделялось внимание лишь отдельным институтам. Важно отметить, отсутствие устоявшегося доктринального подхода на сущность новых правовых институтов цифровой экономики, что отчасти затрудняет фрормирование соответствующей правовой среды. Важными возникающими вопросами при фрормировании правовой доктрины, а в дальнейшем и нормативно-правовой базы, являются: во-первых, создание ясных представлений об отраслевом регулировании, какие общественные отношения будут относиться к ведению гражданского права, а какие к финансовому праву и другим отраслям права и законодательства; во-вторых, нельзя забывать о необходимости создания единого структурообразующего законодательного акта, а также комплекса норм и институтов, которые войдут в Гражданский кодекс РФ, Налоговый кодекс РФ, и другие законодательные и подзаконные нормативные акты России. Именно таким образом должно быть закреплено цифровое право, дающее, прежде всего, определения новым явлениям цифрровой жизни и регламентирующее вопросы совершения сделок с цифровыми деньгами и правами, а также решающее проблемы налогообложения и финансовой дисциплины.

В Стратегии научно-технологического развития Российской Федерации, утвержденной Указом Президента РФ от 1 декабря 2016 года № 642, констатируются проблемы невосприимчивости нашей экономики и нашего общества к инновациям [8]. Действительно, такая серьезная проблема существует и касается она также законодательной сферы. Сегодняшняя необходимость создания новых объектов экономических отношений, сопровождается на наш взгляд, некой «консервативностью права». Как указывает А. Н. Лысенко, правовое регулирование в большинстве случаев не должно опережать развитие экономики должно опираться на привычные, проверенные правовые категории, тем самым оптимизировать поступательное экономическое развитие новых институтов [5].

Хотелось бы отметить, что существующие правовые доктрины не имеют для освоения столь активных процессов цифровизации экономики соответствующего концептуального аппарата. Если внесение изменений в законодательные акты, как правило, не представляет особых трудностей 
для законодателя ни в организационном, ни во временном отношении, то изменение правовых доктрин - процесс гораздо более сложный, поэтому скорее всего законодательные изменения в соответствии с современными реалиями придут значительно раньше.

Уже сейчас юридическое сообщество находится в поисках приемлемых правовых инструментов регулирования цифровой экономики. Возможные подходы правового регулирования цифровой среды нашли отражение в положениях Проекта федерального закона № 424632-7 «О внесении изменений в части первую, вторую и четвертую Гражданского кодекса Российской Федерации» (о цифровых правах), внесенных депутатами В. В. Володиным и П. В. Крашенниниковым. В нем предлагалось закрепить в Гражданском кодексе несколько базовых положений, которые позволили бы регулировать рынок новых объектов экономических отношений («цифровые права», «токены», «криптовалюта» и пр.), обеспечить правовые условия для совершения и исполнения сделок в цифровой среде («смарт-контракты), «самоисполняемые» сделки и др.) и предоставить защиту гражданам и юридическим лицам по таким сделкам.

Другой альтернативный проект федерального закона № 419059-7 «О цифровых финансовых активах) дает определения таким цифровым активам, как криптовалюта и токен, законодательно закрепляет вид договора, заключаемый в электронной форме - смарт-контракт, но он пока отклонен.

Один из приведенных законопроектов после основательных доработок, был принят. Государственная Дума в марте в окончательном чтении приняла поправки в Гражданский кодекс РФ, связанные с введением понятия цифровых прав. Принятые поправки вступят в силу уже осенью и наполнят законодательные нормы новым содержанием и смыслом.

Совет при Президенте Российской Федерации по кодификации и совершенствованию гражданского законодательства, обсуждавший проект федерального закона № 424632-7 «О внесении изменений в части первую, вторую и четвертую Гражданского кодекса Российской Федерации» (о цифровых правах) при первоначальном ознакомлении, не поддержал его по концептуальным причинам [11].

Аналогичный вывод был сделан и по поводу проекта федерального закона № 419059-7 «О цифровых финансовых активах». Именитые эксперты отметили, что проект федерального закона № 419059-7 «О цифровых финансовых активах» не может быть поддержан в связи с концептуальными недостатками [10].

Действительно, следует согласиться с мнением ученых о том, что «многие экономические и технологические модели отношений не являются еще устоявшимися, появляясь, видоизменяясь и отчасти исчезая из хозяйственной практики». В связи с этим, по их мнению, изложенному в экспертном заключении, представляется преж- девременным установление базовых понятий в кодификационном акте, поскольку они еще не являются устоявшимися не только в науке и юриспруденции, но и в экономике [11]

Вместе с тем, необходимость ускорения пра вовой определённости в вопросах цифровой экономики является очевидной. Активные процессы цифровизации требуют формирования «новой регуляторной среды, обеспечивающей благоприятный правовой режим для возникновения и развития современных технологий а также для осуществления экономической деятельности, связанной с их использованием в цифровой экономике» [3, с. 6-7]. Важно провести систематизацию действующих нормативно-правовых актов, регулирующих правовые отношения в сфере формирования цифровой экономики а также подготовить структурообразующий нормативный правовой акт, устанавливающий базовые нормативные правила реализации институтов цифровой экономики. В сложившейся ситуации необходимо сформировать и усовершенствовать понятийно-категориальный аппарат в области цифровой экономики, провести гармонизацию подходов к нормативному правовому регулированию цифровой экономики с учетом опыта зарубежных стран.

В настоящее время существует правовой вакуум в сфере регулирования цифровой экономики. От этого страдают любые субъекты общественных отношений с использованием цифровых технологий в экономике. С одной стороны, могут пострадать законопослушные и добросовестные субъекты гражданских правоотношений, с другой стороны отсутствие четкого финансово-правового регулирования приводит к уклонению от налогообложения. Проблемы правового регулирования цифровой экономики принимают международный масштаб, поскольку привязать деятельность крупнейших интернет-платформ к конкретному государству не всегда бывает просто, в том числе из-за внедрения в экономику новых цифровых бизнес-моделей.

Важно понимать, что цифровые объекты постоянно эволюционируют. Криптолвалюта сегодня является альтернативным денежным обращением, получившим большую популярность. Большинство отмечают, что рынок криптовалют является одним из самых перспективных направлений развития мировой экономики. Следует понимать, что процесс проникновения криптовалюты в жизнь сложно остановить, а отказ от нее может препятствовать развитию цифровой экономики, поэтому разуменее придать цифровой валюте правовую определённость и статус. Подготовка законодательства по поводу применения криптоденег должна продолжаться с учетом мнения научного сообщества. Придание криптовалюте официального правового статуса позволит публичной власти контролировать ее оборот

Представители Совета при Президенте Российской Федерации по кодификации и совершенствованию гражданского законодательства в вышеупомянутом экспертном заключении отмечают, 
что юридический френомен криптовалюты является малоисследованным в современной российской науке гражданского права, находится еще в стадии его становления и поспешное установление легальной дефиниции чревато негативными последствиями. Допустимость сделок с криптовалютой, равно как установление гражданского права на нее, предопределяется, по их мнению не столько гражданско-правовыми критериями сколько публично-правовыми соображениями политики права.

Безусловно, правовое регулирование криптовалюты с учетом объективных рисков, должно осуществляться исходя из публичных целей государства и нейтрализовать такие негативные процессы, как отмывание доходов, полученных преступным путем, и фринансирование терроризма, а также размывание налоговой базы [4, с. 53-54]

Bce общественные отношения являются динамичными и подвергаются постоянным изменениям, в свою очередь своевременная адаптация законодательства к этим изменениям является залогом успешности, качественности. Соответственно, законы должны развиваться адекватно и меняться в соответствии с изменениями социально-политической и экономической жизни страны. К сожалению, отсутствие системности в вопросах правового обеспечения активной цифровизации, пока налицо. В ближайшее время следует решить ряд проблем правового характера для того, чтобы цифровая экономика не навредила государству и его гражданам

Во-первых, принять единый законодательный акт, устанавливающий определения новым явлениям в экономике: цифровизации, цифровому праву, цифровым деньгам, токену, криптовалюте блокчейну и другим, а также закрепляющий основные принципы налогообложения и осуществления сделок с цифровыми деньгами и правами.

Во-вторых, разработать ряд норм, которыми необходимо дополнить Гражданский кодекс РФ и Налоговый кодекс РФ, направленных на детализацию правового регулирования отношений в сфере цифровой экономики, в том числе определить, что будет подразумеваться под цифровым постоянным представительством применительно к бизнес-субъектам.

В-третьих, подготовить предложения для формирования международно-правовой базы и выработки подхода к справедливому налогообложению цифровой экономики.

Таким образом, пока наблюдается очевидная бессистемность российского законодательства, действующие правовые регуляторы не приспособлены к регламентации цифровой сферы, которая быстро занимает лидирующие позиции во многих областях [6, с. 33-34]. Наблюдается расширение сореры правового регулирования, появление новых субъектов - цифровых личностей, поскольку с самого рождения лицо будет попадать в цифровое пространство и его статус моментально будет отражаться в виртуальной среде. Бумажные деньги и национальная валюта уходят в прошлое, дематериализуются и существуют в электронной форме. В складывающихся условиях всеобъемлющей цифровизации важно понимать, что правильно организованные финансово-правовые отношения в цифровую эпоху может предоставить большие возможности для увеличения благосостояния людей, лишь находясь в надежном правовом поле.

\section{Литература}

1. Антон Вашкевич. Смарт контракты: что и зачем // URRL: https://www.simplawyer.com/wp-content/uploads/ simplawyer.com-\%E2\%80\%94-\%D0\%A1\%D0\%BC\%D0\%B0\%D1\%80\%D1\%82-\%D0\%BA\%D0\%BE\%D0\%BD\%D1\%82 \%D1\%80\% D0\%B0\%D0\%BA\%D1\%82\%D1\%8B.-\%D0\%97\%D0\%B0\%D1\%87\%D0\%B5\%D0\%BC-\%D0\%B8-\%D0\%BA\%D0\%B0\%D0\%BA-Demo-1 .0.pdf (Дата обращения 10.03.2019).

2. Быков А. Ю. Право цифровой экономики: некоторые народно-хозяйственные и политические риски. Москва: Проспект, 2018. 355 c.

3. Вайпан В. А. Основы правового регулирования цифровой экономики // Право и экономика. 2017. №11. С.5-18

4. Левашенко А. Д., Ермохин И. С., Коваль А. А. Концепция развития криптоэкономики в России // Предпринимательское право. Приложение «Право и Бизнес». 2018. №1. С.52-56.

5. Лысенко А. Н. Имущество в гражданском праве России. М.: Деловой двор, 2010. 134 с

6. Право в условиях цифровизации / Т. Я. Хабриева. СПб.: СПбГУП, 2019. 36 с

7. Распоряжение Правительства РФ от 28.07.2017 № 1632-р «Об утверждении программы «Цифровая экономика Российской Федерации» // Собрание законодательства РФ. 07.08.2017. № 32. ст. 5138.

8. Указ Президента РФ от 01.12.2016 №642 «О Стратегии научно-технологического развития Российской Федерации» URL: http://kremlin.ru/acts/bank/41449 (Дата обращения: 10.03.2019).

9. Экспертное заключение Совета при Президенте Российской Федерации по кодификации и совершенствованию гражданского законодательства по проекту федерального закона № 424632-7 «О внесении изменений в части первую, вторую и четвертую Гражданского кодекса Российской Федерации» URL: http://privlaw.ru/wp-content/uploads/2018/04/ meeting-190418-zakonoproekt-2-project-conclusion.pdf (Дата обращения: 10.03.2019).

10. Экспертное заключение Совета при Президенте Российской Федерации по кодификации и совершенствованию гражданского законодательства по проекту федерального закона № 419059-7 «О цифровых финансовых активах» URL: http://privlaw.ru/wp-content/uploads/2018/04/meeting-190418-zakonoproekt-6-project-conclusion.pdf (Дата обращения: 10.03.2019).

11. Экспертное заключение Совета при Президенте Российской Федерации по кодификации и совершенствованию гражданского законодательства по проекту федерального закона № 424632-7 «О внесении изменений в части первую, вторую и четвертую Гражданского кодекса Российской Федерации», подготовленное С. В. Сарбаш, Н. Г. Семилютина 
URL: http://privlaw.ru/wp-content/uploads/2018/04/meeting-190418-zakonoproekt-2-project-conclusion.pdf (Дата обращения: 10.03.2019).

\section{References}

1. Anton Vashkevich. Smart kontrakty: chto i zachem (Smart contracts: what and why) // URRL: https://www.simplawyer com/wp-content/uploads/simplawyer.com-\%E2\%80\%94-\%D0\%A1\%D0\%BC\%D0\%B0\%D1\%80\%D1\%82-\%D0\%BA\%D0\% BE\%D0\%BD\%D1\%82\%D1\%80\%D0\%B0\%D0\%BA\%D1\%82\%D1\%8B.-\%D0\%97\%D0\%B0\%D1 \%87\%D0\%B5\%D0\%BC\%D0\%B8-\%D0\%BA\%D0\%B0\%D0\%BA-Demo-1.0.pdf (Accessed: 10.03.2019). (In Russian).

2. Bykov A. Yu. Pravo cifrovoj ekonomiki: nekotorye narodno-hozyajstvennye i politicheskie riski (The right of the digital economy: some national economic and political risks). Moscow: Prospekt, 2018. 355 p. (In Russian).

3. Vajpan V. A. Osnovy pravovogo regulirovaniya cifrovoj ekonomiki (Basics of legal regulation of the digital economy) /I Pravo i ekonomika. 2017. No.11. P.5-18. (In Russian).

4. Levashenko A. D., Ermohin I. S., Koval' A. A. Koncepciya razvitiya kriptoekonomiki v Rossii (The concept of the development of cryptoeconomics in Russia) // Predprinimatel'skoe pravo. Prilozhenie «Pravo i Biznes». 2018. No.1. P. 5256. (In Russian).

5. Lysenko A. N. Imushchestvo v grazhdanskom prave Rossii (Property in the civil law of Russia). Moscow: Delovoj dvor, 2010. 134 p. (In Russian).

6. Pravo v usloviyah cifrovizacii (Law in terms of digitalization) / T. Ya. Habrieva. St.Petersburg: SPbGUP publ., 2019. 36 p. (In Russian).

7. Rasporyazhenie Pravitel'stva RF ot 28.07.2017 №1632-r «Ob utverzhdenii programmy «Cifrovaya ekonomika Rossijskoj Federacii) (On approval of the program "Digital Economy of the Russian Federation) // Sobranie zakonodatel'stva RF. 07.08.2017. No.32. Art. 5138. (In Russian).

8. Ukaz Prezidenta RF ot 01.12.2016 № 642 «O Strategii nauchno-tekhnologicheskogo razvitiya Rossijskoj Federacii») (On the Strategy of Scientific and Technological Development of the Russian Federation) URL: http://kremlin.ru/acts/bank/41449 (Accessed: 10.03.2019). (In Russian).

9. Ekspertnoe zaklyuchenie Soveta pri Prezidente Rossijskoj Federacii po kod fikacii i sovershenstvovaniyu grazhdanskogo zakonodatel'stva po proektu federal'nogo zakona № 424632-7 «O vnesenii izmenenij v chasti pervuyu, vtoruyu i chetvertuyu Grazhdanskogo kodeksa Rossijskoj Federacii), (On Amendments to Parts One, Two and Four of the Civil Code of the Russian Federation) URL: http://privlaw.ru/wp-content/uploads/2018/04/meeting-190418-zakonoproekt-2-project-conclusion.pdf (Accessed: 10.03.2019). (In Russian).

10. Ekspertnoe zaklyuchenie Soveta pri Prezidente Rossijskoj Federacii po kodifikacii i sovershenstvovaniyu grazhdanskogo zakonodatel'stva po proektu federal'nogo zakona № 419059-7 «O cifrovyh finansovyh aktivah» (On digital financial assets) URL: http://privlaw.ru/wp-content/uploads/2018/04/meeting-190418-zakonoproekt-6-project-conclusion.pdf (Accessed: 10.03.2019). (In Russian).

11. Ekspertnoe zaklyuchenie Soveta pri Prezidente Rossijskoj Federacii po kodifikacii i sovershenstvovaniyu grazhdanskogo zakonodatel'stva po proektu federal'nogo zakona № 424632-7 «O vnesenii izmenenij v chasti pervuyu, vtoruyu i chetvertuyu Grazhdanskogo kodeksa Rossijskoj Federacii), podgotovlennoe S. V. Sarbash, N. G. Semilyutina. (On Amendments to Parts One, Two and Four of the Civil Code of the Russian Federation) URL: http://privlaw.ru/wp-content/uploads/2018/04/meeting190418-zakonoproekt-2-project-conclusion.pdf (Accessed: 10.03.2019). (In Russian).

\section{Информация об авторах}

Смирнов Дмитрий Анатольевич - доктор юридических наук, профессор, директор юридического института Северо-Кавказского федерального университета (Ставрополь) / dmi197526@ yandex.ru

Боташева Лейла Эмербековна - кандидат юридических наук, доцент кафедры административного и финансового права юридического института Северо-Кавказского федерального университета (Ставрополь) / botasheval@gmail.com

Леонов Алексей Николаевич - судья Ставропольского краевого суда (Ставрополь) / 411ga@mail.ru

\section{Information about the authors}

Smirnov Dmitrii - Doctor of Law, Director of the Institute of Law, North-Caucasus Federal University (Stavropol) / dmi197526@yandex.ru

Botasheva Leila - PhD in Law, Associate Professor, Chair of Administrative and Financial Law, Institute of Law, NorthCaucasus Federal University (Stavropol) / botasheval@gmail.com

Leonov Alexey - judge, Stavropol Regional Court (Stavropol) / 411 ga@mail.ru 